\title{
Intra-coronary morphine versus placebo in the treatment of acute ST-segment elevation myocardial infarction: the MIAMI randomized controlled trial
}

Philippe Le Corvoisier ${ }^{1,2^{*}+}$ (D), Romain Gallet ${ }^{2,3 \dagger}$, Pierre-François Lesault ${ }^{3}$, Etienne Audureau ${ }^{4}$, Muriel Paul ${ }^{5}$, Julien Ternacle ${ }^{3}$, Saïd Ghostine ${ }^{6}$, Stéphane Champagne ${ }^{3}$, Raphaele Arrouasse ${ }^{1}$, Dalila Bitari ${ }^{1}$, Gauthier Mouillet ${ }^{3}$, Jean-Luc Dubois-Randé2,7, Alain Berdeaux², Bijan Ghaleh², Jean-François Deux ${ }^{8}$ and Emmanuel Teiger ${ }^{2,3}$

\begin{abstract}
Background: Experimental studies suggest that morphine may protect the myocardium against ischemiareperfusion injury by activating salvage kinase pathways. The objective of this two-center, randomized, doubleblind, controlled trial was to assess potential cardioprotective effects of intra-coronary morphine in patients with STsegment elevation myocardial infarction (STEMI) referred for primary percutaneous intervention.

Methods: Ninety-one patients with STEMI were randomly assigned to intracoronary morphine $(1 \mathrm{mg})$ or placebo at reperfusion of the culprit coronary artery. The primary endpoint was infarct size/left ventricular mass ratio assessed by magnetic resonance imaging on day $3-5$. Secondary endpoints included the areas under the curve (AUC) for troponin $T$ and creatine kinase over three days, left ventricular ejection fraction assessed by echocardiography on days 1 and 6, and clinical outcomes.
\end{abstract}

Results: Infarct size/left ventricular mass ratio was not significantly reduced by intracoronary morphine compared to placebo $(27.2 \% \pm 15.0 \%$ vs. $30.5 \% \pm 10.6 \%$, respectively, $p=0.28)$. Troponin T and creatine kinase AUCs were similar in the two groups. Morphine did not improve left ventricular ejection fraction on day 1 (49.7 $\pm 10.3 \%$ vs. 49 . $3 \pm 9.3 \%$ with placebo, $p=0.84)$ or day $6(48.5 \pm 10.2 \%$ vs. $49.0 \pm 8.5 \%$ with placebo, $p=0.86)$. The number of major adverse cardiac events, including stent thrombosis, during the one-year follow-up was similar in the two groups.

Conclusions: Intracoronary morphine at reperfusion did not significantly reduce infarct size or improve left ventricular systolic function in patients with STEMI. Presence of comorbidities in some patients may contribute to explain these results.

Trial registration: ClinicalTrials.gov, NCT01186445 (date of registration: August 23, 2010).

Keywords: STEMI, Reperfusion injury, Cardioprotection, Infarct size, Morphine

\footnotetext{
* Correspondence: philippe.lecorvoisier@aphp.fr

tPhilippe Le Corvoisier and Romain Gallet contributed equally to this work.

'Department VERDI, Inserm, CIC1430, AP-HP, Henri Mondor Hospital, 51

Avenue du Maréchal de Lattre de Tassigny, F-94010 Creteil, France

${ }^{2}$ Inserm, U955 team 3, F-94010 Creteil, France

Full list of author information is available at the end of the article
}

(c) The Author(s). 2018 Open Access This article is distributed under the terms of the Creative Commons Attribution 4.0 International License (http://creativecommons.org/licenses/by/4.0/), which permits unrestricted use, distribution, and reproduction in any medium, provided you give appropriate credit to the original author(s) and the source, provide a link to the Creative Commons license, and indicate if changes were made. The Creative Commons Public Domain Dedication waiver (http://creativecommons.org/publicdomain/zero/1.0/) applies to the data made available in this article, unless otherwise stated. 


\section{Background}

Ischemic heart disease is the leading cause of morbidity and mortality worldwide. Although the prognosis of ST-segment elevation myocardial infarction (STEMI) has improved significantly in recent years [1], heart failure remains a common complication [2]. Early reperfusion of the infarct-related artery is the cornerstone of the modern treatment of STEMI. However, reperfusion of the ischemic myocardium can induce additional cell damage by triggering various abrupt biochemical changes $[3,4]$, including generation of reactive oxygen species, calcium overload, and opening of the mitochondrial permeability transition pore (mPTP) [4]. These mechanisms induce the death of cardiomyocytes that were viable at the end of the ischemic period, thereby exacerbating the myocardial injury [3]. Treatments to prevent or treat ischemia-reperfusion injury may therefore be of major clinical interest.

Morphine holds promise for preventing ischemia-repe rfusion injury. Several experimental studies in rodents showed a reduction in infarct size after morphine injection at the time of reperfusion $[5,6]$. The cardioprotective effects of morphine involve activation of the PI3-kinase pathway which enhances mitochondrial resistance to calcium overload and inhibits MPTP opening [6]. Other data suggest a role for nitric oxide and $\mathrm{K}_{\mathrm{ATP}}$ channels [7, 8]. Similar cardioprotective effects have been reported for other opioid receptors agonists such as remifentanil [9].

The aim of this randomized, double-blind, placebo-con trolled, two-center study in patients with STEMI was to evaluate whether intracoronary morphine administration at the time of reperfusion diminished myocardial injury assessed by magnetic resonance imaging (MRI).

\section{Methods}

This randomized double-blind placebo-controlled trial compared intracoronary morphine to placebo in patients with STEMI.

\section{Study population}

Eligible patients were men and women with STEMI referred for primary percutaneous coronary intervention (PCI) within $6 \mathrm{~h}$ after chest symptom onset. STEMI was defined as chest pain lasting more than $15 \mathrm{~min}$ with at least one of the following criteria: ST elevation $\geq 1 \mathrm{~mm}$ in at least two contiguous leads or presumed or certain appearance of a Q wave in three contiguous leads. Only patients with a TIMI coronary flow score of 0 on the first angiogram were included. Exclusion criteria were fibrinolysis, known allergy to morphine hydrochloride, uncontrolled epilepsy, brain injury or intracranial hypertension, previous STEMI or coronary artery bypass grafting (CABG), resuscitated cardiac arrest, cardiogenic shock or mechanical ventilation at admission, mechanical complication, sustained ventricular arrhythmia, high-grade atrioventricular block, decompensated respiratory insufficiency, serious hepatocellular insufficiency, and contraindication to cardiac MRI or gadolinium injection.

The study was performed in accordance with the ethical principles stated in the Declaration of Helsinki. The protocol was approved by the institutional review board of Pitie-Salpetriere hospital and all patients gave written informed consent. All data were measured off-line by a physician blinded to group allocation.

\section{Percutaneous coronary intervention}

Patients in both the morphine and placebo groups routinely received intravenous aspirin and a loading dose of P2Y12 inhibitors before PCI. Intravenous heparin was administered to maintain an activated clotting time $>250 \mathrm{~s}$.

All coronary angiography and stent implantation procedures were performed using standard interventional techniques. Thromboaspiration, balloon predilation, stent type selection, and use of glycoprotein IIb/IIIa inhibitors were at the operators' discretion.

\section{Randomization procedure and study treatment administration}

Randomization (1:1) sequences were generated by the biostatistician using random number tables and stratified by center using random blocks of 4 . Pharmacists prepared sequentially numbered identical syringes of morphine (1 $\mathrm{mg}$ in $3 \mathrm{~mL}$ of saline) or placebo ( $3 \mathrm{~mL}$ of saline) according to the randomization sequence. Interventional cardiologists were blinded to allocation group. The study treatment was administered immediately after the artery was reopened (TIMI flow 2 or 3 ).

\section{MRI protocol}

MRI was performed between day 3 and day 5 on a clinical $1.5 \mathrm{~T}$ system (Magnetom Avanto; Siemens Healthcare; Erlangen; Germany) using a 6-channel phased-array cardiac coil to assess myocardial injury. Unenhanced cine Steady State Free Precession (SSFP) sequences were acquired in the short axis plane. Eight to 10 sections encompassing the left ventricle were acquired for each patient. T2W-short tau inversion recovery (T2W-STIR) sequences were acquired in the short axis section covering the whole left ventricle using the following parameters (voxel size $2 \times 1.5 \times 8 \mathrm{~mm}$, flip angle $90 / 180^{\circ}$, effective echo time $47 \mathrm{~ms}$, bandwidth $235 \mathrm{~Hz} /$ pixel). Fifteen minutes after injection of $0.2 \mathrm{mmol} / \mathrm{Kg}$ of gadolinium (Dotarem; Guerbet; Aulnay sous Bois; France), late gadolinium enhanced (LGE) images were acquired using a segmented three-dimensional IR Gradient Echo T1-weighted technique. Left ventricular (LV) end-diastolic and end-systolic volume indexes and ejection fraction were 
measured from SSFP images using dedicated software (SyngoVia; Siemens Healthcare). The extent of myocardial edema was quantified on the T2W images using semiautomatic detection with the full width at half-maximum approach on a dedicated software (cvi42; Circle Cardiovascular Imaging Inc., Calgary, Alberta, Canada). Same approach (full width at half-maximum method) was used to calculate infarct size. LV mass was calculated by countering inner and outer boundaries of the LV wall on LGE images. Infarct size and LV mass were expressed in grams (myocardial density: $1.05 \mathrm{~g} / \mathrm{ml}$ ). The relative proportion of myocardial infarction was calculated by dividing infarct size by total LV mass.

\section{Transthoracic echocardiography}

Transthoracic echocardiography was performed on days 1 and 6. Left ventricular ejection fraction (LVEF) was calculated from parasternal long axis and apical four-chamber views using the biplane Simpson's method.

\section{Study endpoints}

The primary endpoint was infarct size/LV mass ratio measured by MRI between days 3 and 5 . Secondary endpoints included the ratio of infarct size over area at risk measured by MRI, the areas under the curves (AUCs) of serum creatine kinase and troponin $\mathrm{T}$ levels (measured every $4 \mathrm{~h}$ during the first $24 \mathrm{~h}$ then every $6 \mathrm{~h}$ during the next $48 \mathrm{~h}$ ), LVEF measured by echocardiography on days 1 and 6, infarct size/LV mass ratio by MRI after 1 year, and clinical outcome after 3 months and 1 year.

\section{Sample size estimation}

A previous study reported a mean infarct size measured by MRI of $14 \% \pm 6 \%$ of LV mass [10]. The estimated relative decrease in infarct size/LV mass after intracoronary morphine in preclinical studies was at least 33\% [6]. To have $90 \%$ power for detecting a $33 \%$ decrease with alpha set at 5\%, 36 patients were needed in each group. Assuming that $30 \%$ of patients would not be evaluable (e.g., due to a contraindication to MRI, consent withdrawal, or poor MRI acquisition), 91 patients were included in this study.

\section{Statistical analysis}

Continuous variables are described as mean \pm standard deviation and categorical variables as numbers (\%). For the primary outcome, patients were assessed according to randomized treatment group under the intent-to-treat (ITT) principle. Continuous variables were compared using the Student or Mann-Whitney test, depending on the normality of distributions as assessed by the Shapiro-Wilk test, and categorical variables using the chi-square test or Fisher's exact test, as appropriate. Pearson or Spearman correlation coefficients were computed to assess relationships between selected continuous parameters (i.e. troponin $\mathrm{T}$ and creatine kinase AUCs against infarct size/ left ventricular mass ratio), as appropriate. All $p$ values were two-sided, and $p$ values lower than 0.05 were considered statistically significant. All analyses were performed using Stata V14.1 (StataCorp, College Station, TX, USA).

\section{Results \\ Population characteristics}

We included 91 patients with STEMI, who were randomly assigned to intracoronary injection of either morphine or placebo at the time of reperfusion. One patient withdrew consent after study inclusion, leaving $90 \mathrm{pa}-$ tients in the intention-to-treat population (Fig. 1).

There was no difference in baseline characteristics and concomitant therapies between both groups. The distribution of the culprit arteries was well balanced between the two arms. Most patients (93.3\%) received glycoprotein (GP) IIb/IIIa receptor inhibitors or bilavirudin (Table 1).

\section{Safety of intracoronary injection}

Intracoronary injection of the study medication was associated with asymptomatic hypotension in two patients, one in each group. At the end of the procedure, the groups had no significant differences in rates of slow flow, distal embolism, or intra-stent residual thrombosis. The proportions of patients with myocardial blush grade II (21.1\% vs. $30.0 \%$ in morphine and placebo groups, respectively) or III ( $47.4 \%$ vs. $40.0 \%)$ were similar in the two groups $(p=0.96)$ (Table 2).

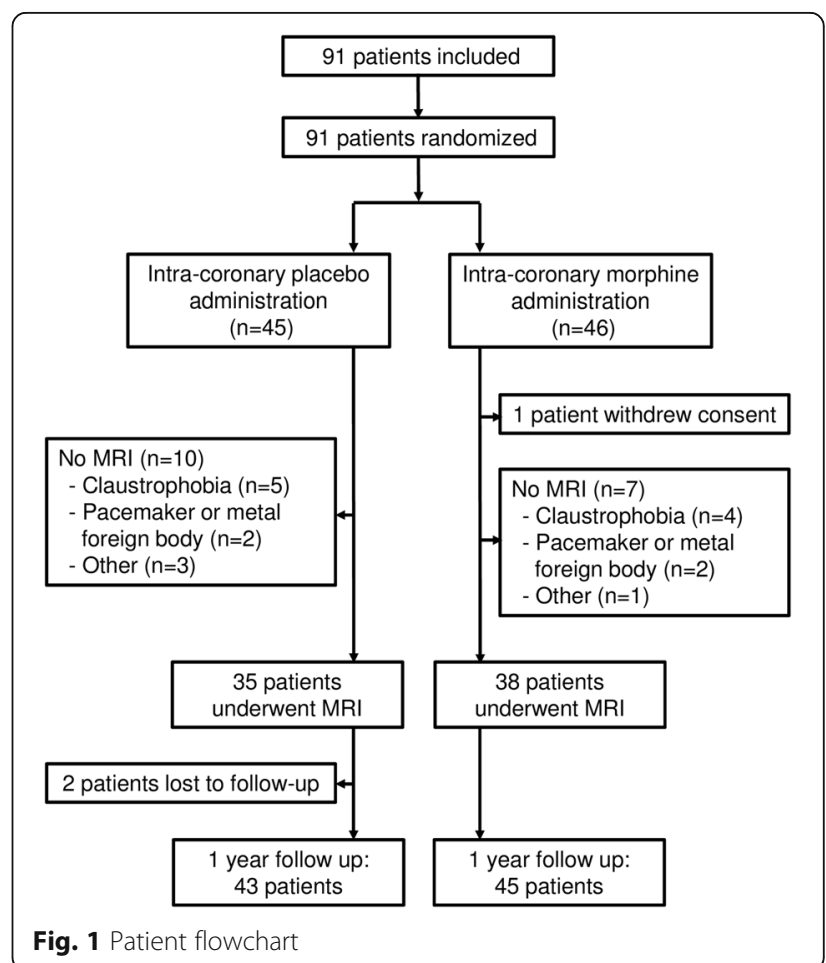


Table 1 Patient characteristics

\begin{tabular}{|c|c|c|}
\hline & $\begin{array}{l}\text { Morphine group } \\
(n=45)\end{array}$ & $\begin{array}{l}\text { Placebo group } \\
(n=45)\end{array}$ \\
\hline \multicolumn{3}{|l|}{ Patient characteristics } \\
\hline Age, $y^{a}$ & $59.9 \pm 13.2$ & $56.5 \pm 10.6$ \\
\hline Male/female, n (\%) & $36(80.0) / 9(20.0)$ & $37(82.2) / 8(17.8)$ \\
\hline Diabetes mellitus, n (\%) & $8(17.8)$ & $5(11.1)$ \\
\hline Hypercholesterolemia, n (\%) & $14(31.1)$ & $13(28.9)$ \\
\hline Smokers (current or former), n (\%) & $33(73.3)$ & $31(68.8)$ \\
\hline Hypertension, n (\%) & $20(44.4)$ & $16(35.6)$ \\
\hline Body mass index, $\mathrm{kg} / \mathrm{m}^{2}$ a & $27.0 \pm 4.1$ & $26.0 \pm 2.9$ \\
\hline \multicolumn{3}{|l|}{ Medical history, n (\%) } \\
\hline History of coronary artery disease & $4(8.9)$ & $4(8.9)$ \\
\hline History of heart failure & $0(0.0)$ & $0(0.0)$ \\
\hline \multicolumn{3}{|l|}{ Clinical characteristics } \\
\hline Symptom-to-balloon time, min ${ }^{a}$ & $189 \pm 87$ & $193 \pm 108$ \\
\hline Killip class > 1, n (\%) & $1(2.2)$ & $1(2.2)$ \\
\hline Sustained ventricular arrhythmia before admission, $n(\%)$ & $0(0.0)$ & $2(4.4)$ \\
\hline \multicolumn{3}{|l|}{ Location of the culprit lesion, $\mathrm{n}(\%)$} \\
\hline Left anterior descending artery & $23(51.1)$ & $20(44.4)$ \\
\hline Circumflex coronary artery & $4(8.9)$ & $8(17.8)$ \\
\hline Right coronary artery & $18(40.0)$ & $17(37.8)$ \\
\hline \multicolumn{3}{|l|}{ Rentrop score, n (\%) } \\
\hline 0 & $28(62.2)$ & $29(64.5)$ \\
\hline 1 & $10(22.2)$ & $10(22.2)$ \\
\hline $2-3$ & $7(15.6)$ & $6(13.3)$ \\
\hline \multicolumn{3}{|l|}{ Number of diseased vessels, n (\%) } \\
\hline 1 & $34(75.6)$ & $36(80.0)$ \\
\hline$\geq 2$ & $11(24.4)$ & $9(20.0)$ \\
\hline \multicolumn{3}{|l|}{ Concomitant therapy, n (\%) } \\
\hline Aspirin & $45(100.0)$ & $44(97.8)$ \\
\hline P2Y12 receptor blockers & $44(97.8)$ & $44(97.8)$ \\
\hline GPIlb-IIla receptor inhibitors/bilavirudin & $22(48.9) / 20(44.4)$ & $26(57.7) / 16(35.6)$ \\
\hline Intravenous morphine injection & $11(24.4)$ & $11(24.4)$ \\
\hline
\end{tabular}

${ }^{\mathrm{a} M e a n} \pm \mathrm{SD}$

Table 2 Safety of intracoronary injection

\begin{tabular}{|c|c|c|c|}
\hline & $\begin{array}{l}\text { Morphine group } \\
(n=45)\end{array}$ & $\begin{array}{l}\text { Placebo group } \\
(n=45)\end{array}$ & $P$ value \\
\hline \multicolumn{4}{|l|}{ Safety of IC injection, n (\%) } \\
\hline Hypotension & $1(2.2)$ & $1(2.2)$ & 1.00 \\
\hline Ventricular arrhythmia & $0(0.0)$ & $0(0.0)$ & 1.00 \\
\hline \multicolumn{4}{|l|}{$\mathrm{PCl}$ results, $\mathrm{n}(\%)$} \\
\hline Slow flow & $1(2.2)$ & $1(2.2)$ & 1.00 \\
\hline Intra-stent residual thrombosis & $3(6.7)$ & $7(15.6)$ & 0.18 \\
\hline Distal embolism & $2(4.4)$ & $3(6.7)$ & 1.00 \\
\hline
\end{tabular}




\section{Infarct size}

Myocardial injury was assessed by MRI (Fig. 1). Infarct size/LV mass ratio was not significantly improved by intracoronary morphine $(27.2 \pm 15.0 \%$ vs. $30.5 \pm 10.6 \%$ with placebo, $p=0.28$ ). Infarct size remained similar in the two groups when adjusted on the area at risk (Table 3). A per-protocol analysis led to the same conclusion as did the intention-to-treat analysis.

These results are supported by cardiac enzyme release. Morphine did not significantly reduce $\mathrm{AUC}_{0-72 \mathrm{~h}}$ values for troponin $\mathrm{T}(70,979 \quad[36,726-100,070]$ A.U. vs. 61,443 $[46,330-97,460]$ A.U. with placebo, $p=0.71)$ and creatine kinase $\quad(18,815 \quad[11,829-28,389] \quad$ A.U. vs. 18,721 [13,515-25,994] A.U. with placebo, $p=0.79)$. Neither were peak troponin $\mathrm{T}$ or creatine kinase values significantly different (Fig. 2). Infarct size assessed by MRI correlated strongly with enzyme release (troponin T: $r=0.73, p<0.0001$; creatine kinase: $r=0.68, p<0.0001)$.

\section{Left ventricular systolic function}

LVEF assessed by echocardiography was similar in the morphine and placebo groups on day $1(49.7 \% \pm 10.3 \%$ vs. $49.3 \% \pm 9.3 \%, p=0.84)$ and day $6(48.5 \% \pm 10.2 \%$ vs. $49.0 \% \pm 8.5 \%, p=0.86)$. The percentage of patients with LV systolic dysfunction defined as LVEF below 45\% was not significantly lower with morphine $(29.5 \%$ vs $26.7 \%$ with placebo, $p=0.76)$. Diastolic function assessed based on the E/E' ratio was similar in the two groups $(8.2 \pm 2.5$ vs $7.9 \pm 3.5, p=0.73)$. Similarly, MRI showed no significant differences in LV structural or functional parameters on day 3-5 (Table 3 ).

\section{One-year outcomes}

MRI performed after one year showed similar infarct size/LV mass ratio $(21.4 \pm 9.8 \%$ vs. $23.0 \pm 8.0 \%$ in placebo, $p=0.51)$ and $\operatorname{LVEF}(52.2 \% \pm 10.3 \%$ vs. $53.3 \% \pm$ $11.4 \%, p=0.71$ ) values in the two groups. The frequency of major adverse cardiac events (MACEs) after 12 months was not lower in the morphine group: MACEs occurred in 7 (15.6\%) patients in the morphine

Table 3 Myocardial injury assessed by MRI

\begin{tabular}{llll}
\hline & $\begin{array}{l}\text { Morphine group } \\
(n=38)\end{array}$ & $\begin{array}{l}\text { Placebo group } \\
(n=35)\end{array}$ & $P$ value \\
\hline LV mass, g & $131 \pm 34$ & $128 \pm 33$ & 0.63 \\
Infarct size, g & $36.6 \pm 22.5$ & $39.5 \pm 17.7$ & 0.54 \\
Infarct size/LV mass, \% & $27.2 \pm 15.0$ & $30.5 \pm 10.6$ & 0.28 \\
Area at risk/LV mass, \% & $31.3 \pm 12.5$ & $36.0 \pm 11.2$ & 0.15 \\
Infarct size/Area at risk, \% & $80.5 \pm 19.4$ & $84.1 \pm 19.5$ & 0.49 \\
LV ejection fraction, \% & $49.2 \pm 11.0$ & $47.6 \pm 8.7$ & 0.50 \\
LV end-diastolic volume, $\mathrm{mL} / \mathrm{m}^{2}$ & $82.2 \pm 16.8$ & $78.4 \pm 21.6$ & 0.41 \\
LV end-systolic volume, $\mathrm{mL} / \mathrm{m}^{2}$ & $42.5 \pm 14.9$ & $41.7 \pm 15.7$ & 0.83 \\
\hline
\end{tabular}

$L V$ left ventricle group and $8(18.6 \%)$ patients in the placebo group. The most common MACE was unplanned admission for decompensated heart failure. Stent thrombosis occurred in one patient in each group. All MACEs were ascribed by the investigators to the underlying cardiovascular disease (Table 4).

\section{Subgroup analyses}

Post-hoc analyses were performed to examine the consistency of results across subgroups and to generate hypotheses to explain the study results. All tests for interaction were non-significant for age, sex, symptom-to-balloon time, and hypercholesterolemia, with $p$ values $>0.20$. Diabetes was common in the study population and may have been a confounder. The test for interaction between diabetes and treatment effect found a $p$ value of 0.17 . An analysis in the subgroup without diabetes showed a trend toward an improvement in the primary endpoint in the morphine group $(22.5 \%$ [14-33] vs. $27.5 \%$ [22-41], $p=0.053)$. In contrast, no effect was evidenced in the subgroup of diabetic patients (35\% [29-48] vs. 31\% [28-36], $p=0.36)$.

\section{Discussion}

The main finding from this randomized controlled trial was that intracoronary morphine, when added to an optimal reperfusion strategy, did not significantly alleviate reperfusion injury or improve secondary endpoints in patients with STEMI. Intracoronary morphine was safe, and serious adverse events occurred with similar frequencies in the two groups.

In recent years, many experimental studies suggested that opioid receptor agonists used in everyday practice might protect the heart against ischemia-reperfusion injury $[5,6]$. A few clinical trials evaluated whether these preclinical data translated into clinical benefits, in various settings. A small pilot study showed a reduction in myocardial ischemia after intracoronary morphine during elective PCI [11]. In another randomized controlled trial in patients with STEMI, intravenous morphine injection combined with remote ischemic postconditioning improved the resolution of ST-segment elevation [12]. In contrast, intracoronary morphine failed to reduce myocardial injury assessed by MRI in an open-label randomized study in patients with STEMI, among whom less than $10 \%$ received GP IIb/IIIa receptor inhibitors [13].

The potential cardioprotective effect of opioid agonists has also been investigated during cardiac surgery. Murphy et al. reported that morphine administration improved LV function recovery after CABG compared to fentanyl [14]. A possible explanation is the greater affinity of morphine for $\delta$-opioid receptor subtypes. Similarly, morphine-induced postconditioning reduced cardiac injury in patient undergoing tetralogy of Fallot 


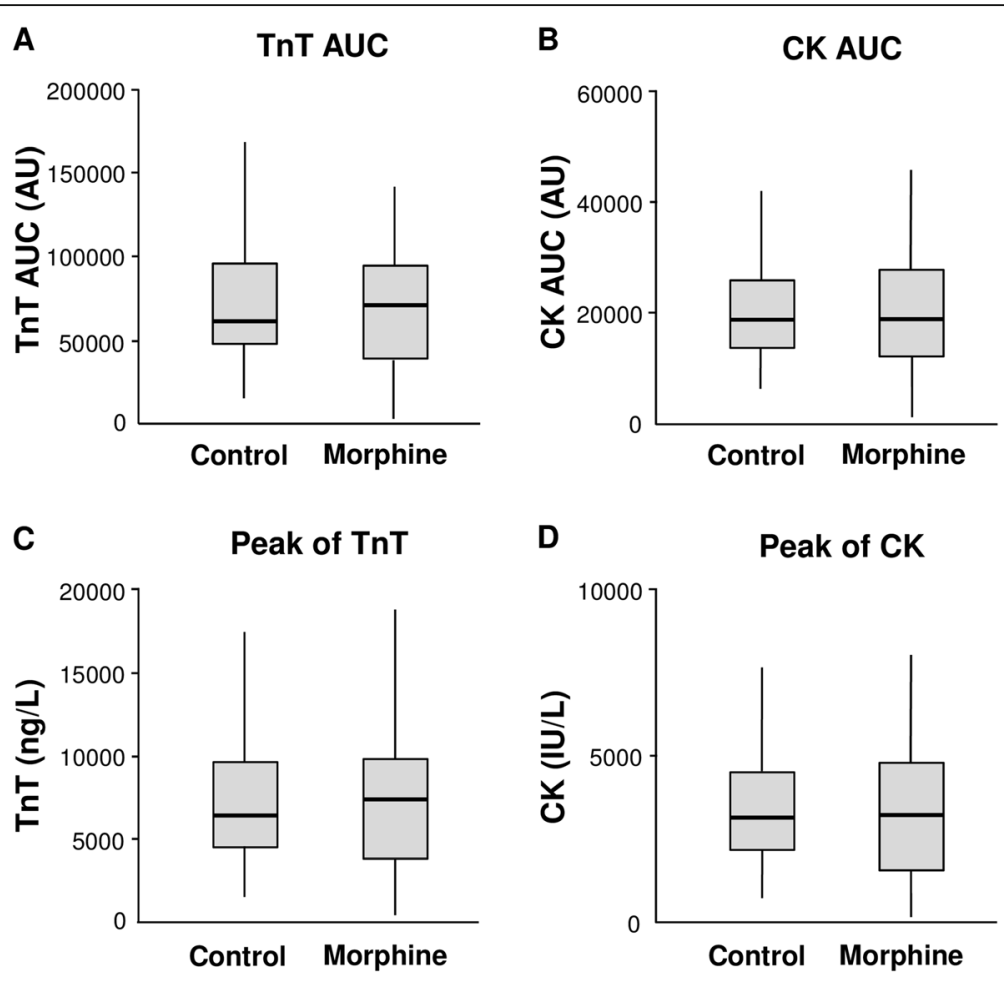

Fig. 2 Areas under the curves and peak of serum troponin T (TnT) (Panel a and $\mathbf{c}$ ) and creatine kinase CK (panel $\mathbf{b}$ and $\mathbf{d}$ ) levels. No difference was observed between groups. Results are shown as boxplots, with each box representing the interquartile range (1st to 3rd quartile, IQR), the line within the box indicating the median, and the whiskers extending to 1.5 times the IQR above and below the box

correction [15]. Another randomized controlled trial demonstrated a cardioprotective effect of the opioid agonist remifentanil during CABG in patients managed with standardized anesthesia protocol [16]. The need for inotropic support after the intervention was reduced in patients given remifentanil. Taken together, these studies suggest that opioid agonists may have a cardioprotective effect during cardiac surgery.
The MIAMI study was designed to assess the potential cardioprotective effects of morphine in STEMI patients. The dose was selected based on previous experimental studies [6]. Intracoronary injection was chosen to allow a rapid activation of target receptors without systemic effect. However, in our study, intracoronary morphine did not significantly reduce reperfusion injury in patients with STEMI undergoing optimal reperfusion therapy.

Table 4 One-year clinical outcomes

\begin{tabular}{lll}
\hline & $\begin{array}{l}\text { Morphine group } \\
(n=45)\end{array}$ & $\begin{array}{l}\text { Placebo group } \\
(n=43)\end{array}$ \\
\hline $\begin{array}{l}\text { Major adverse cardiac events, } \mathrm{n}(\%) \\
\text { Cardiovascular death }\end{array}$ & $7(15.6)$ & $8(18.6)$ \\
Heart failure & $0(0.0)$ & $1(2.3)$ \\
STEMl & $2(4.4)$ & $2(4.6)$ \\
Stable angina & $1(2.2)$ & $1(2.3)$ \\
Sustained ventricular arrhythmia & $3(6.7)$ & $3(7.0)$ \\
Other clinical events, $\mathrm{n}(\%)$ & $1(2.2)$ & $1(2.3)$ \\
Non-cardiovascular death & $5(11.1)$ & $4(9.3)$ \\
CABG & $1(2.2)$ & 0.70 \\
Elective PCl & $1(2.2)$ & $2(4.6)$ \\
\hline CABG corony & $2(4.6)$ \\
\hline
\end{tabular}


Most of the clinical studies designed to translate experimental findings on cardioprotection to clinical settings produced mixed or negative results $[17,18]$. Several hypotheses may explain these discrepancies. Some comorbidities may jeopardize the effectiveness of cardioprotective strategies after myocardial ischemia-reperfusion [19]. In experimental models, the effect of ischemic postconditioning is reduced or even abolished in animal models with hypercholesterolemia or diabetes [20,21]. Loss of cardioprotection was associated with impaired activation of the reperfusion injury salvage kinase pathway [7, 22, 23]. No clinical trial has specifically investigated the effect of pharmacological cardioprotection in patients with comorbidities. However, Yetgin et al. showed in 634 patients treated with multiple balloon inflations during primary $\mathrm{PCI}$, that the effect of ischemic postconditioning was more pronounced in the absence of diabetes [24]. Therefore, we cannot exclude that the presence of comorbidities in some patients contributed to explain our results.

Recently, concern has been raised about the use of intravenous morphine as an analgesic in patients with STEMI [25]. Several studies demonstrated interactions between morphine and P2Y12 receptor inhibitors, leading to impaired gastrointestinal absorption, decreased concentration of active metabolites, and delayed antiplatelet activity [26, 27]. Several strategies have been proposed to overcome this interaction, including concomitant administration of GP IIb/IIIa receptor inhibitors $[25,26]$. The most clinically relevant issue is whether alterations in the pharmacokinetics of P2Y12 receptor inhibitors affect clinical outcomes in patients simultaneously treated with multiple antithrombotic drugs. A subgroup analysis of data from the ATLANTIC study showed that morphine therapy may interact with ST-segment elevation resolution before PCI in patients with STEMI [28]. However, this finding was not associated with a difference in infarct-related artery patency at the time of primary PCI. The impact of preadmission intravenous morphine therapy on patient outcomes was assessed using data from the prospective multicenter nationwide FAST-MI registry [29]. Of the 2438 patients with STEMI, 19\% received morphine. After adjustment for baseline characteristics, morphine therapy did not predict the one-year clinical outcome. Results were similar in the subgroup of patients treated with P2Y12 receptor inhibitors before hospital admission [29]. Similarly, in another cohort of 969 patients with acute anterior STEMI, prehospital morphine therapy was not associated with one-year mortality [30].

Both the route of administration and the dose of morphine differed markedly between these previous studies and the present study. However, our trial adds new evidence to the morphine debate. Intracoronary morphine had no adverse effect on infarct size in randomized patients. Clinical outcomes were similar with morphine and the placebo. The overall rate of serious adverse events was comparable to that seen in a recent similar trial.

One limitation of this study should be noted. Our study was powered to detect a difference in the primary endpoint, and the subgroup analyses remain exploratory.

\section{Conclusions}

The MIAMI trial reported here assessed whether adding intracoronary morphine to optimal PCI diminished reperfusion injury in patients with STEMI. Intracoronary morphine was safe but did not significantly diminish LV infarct size or improve LV systolic function.

\section{Abbreviations}

AUC: Area under the curve; CABG: Coronary artery bypass grafting; GP IIb/Illa receptor inhibitors: Glycoprotein Ilb/Illa receptor inhibitors; LVEF: Left ventricular ejection fraction; mPTP: Mitochondrial permeability transition pore; MRI: Magnetic resonance imaging; PCI: Percutaneous coronary intervention; STEMI: ST-segment elevation myocardial infarction

\section{Acknowledgements}

Not applicable

\section{Funding}

This work was supported by a grant from the French Society of Cardiology. The French Society of Cardiology had no role in the study design, data collection, analysis, interpretation, or writing of the manuscript.

\section{Availability of data and materials}

The datasets used during the current study are available from the

corresponding author on reasonable request in agreement with the French law.

\section{Authors' contributions}

PLC, RG, PFL, EA, MP, JT, SG, SC, RA, DB, GM, JLDR, AB, BG, JFD and ET contributed to the conception and design of the study. PLC, RG, PFL, DB, RA $J \mathrm{LDR}, A B, B G$ and $E T$ were in charge of interpretation of the data and coordination of the study. EA was in charge of the statistical analysis and interpretation of data. MP was in charge of preparation of drugs and assessment of drug stability. JFD performed and interpreted all MRI. JT performed and interpreted all echography. SG, SC, GM, JT, JLDR and ET were in charge of all invasive procedures and interpreted angiographic results. All authors drafted the manuscript or revising it for important intellectual content. All authors approved the manuscript submitted.

\section{Ethics approval and consent to participate}

The study was performed in accordance with the ethical principles stated in the Declaration of Helsinki and good clinical practice principles. The protocol was approved by an ethics committee (institutional review board of the Pitie-

Salpetriere hospital, Paris, France) and all patients gave written informed consent.

Consent for publication

Not applicable

Competing interests

The authors declare that they have no competing interests.

\section{Publisher's Note}

Springer Nature remains neutral with regard to jurisdictional claims in published maps and institutional affiliations.

\section{Author details}

'Department VERDI, Inserm, CIC1430, AP-HP, Henri Mondor Hospital, 51 Avenue du Maréchal de Lattre de Tassigny, F-94010 Creteil, France. ${ }^{2}$ Inserm, U955 team 3, F-94010 Creteil, France. ${ }^{3}$ Interventional Cardiology Unit, AP-HP, Henri Mondor Hospital, F-94010 Creteil, France. ${ }^{4}$ Department of Public Health and CEPIA EA7376, AP-HP, Henri Mondor Hospital, F-94010 Creteil, France. 
${ }^{5}$ Department of Pharmacy, AP-HP, Henri Mondor Hospital, F-94010 Creteil, France. ${ }^{6}$ Department of Cardiology, Marie-Lannelongue Hospital, F-92350 Le Plessis-Robinson, France. ${ }^{7}$ Department of Cardiology, AP-HP, Henri Mondor Hospital, F-94010 Creteil, France. ${ }^{8}$ Department of Radiology, AP-HP, Henri Mondor Hospital, F-94010 Creteil, France.

Received: 5 June 2018 Accepted: 9 October 2018

Published online: 19 October 2018

\section{References}

1. Smolina K, Wright FL, Rayner M, Goldacre MJ. Determinants of the decline in mortality from acute myocardial infarction in England between 2002 and 2010: linked national database study. BMJ. 2012;344:d8059.

2. Sulo G, Igland J, Vollset SE, Nygard O, Ebbing M, Sulo E, et al. Heart failure complicating acute myocardial infarction: burden and timing of occurrence. J Am Heart Assoc. 2016;5:1-8

3. Frohlich GM, Meier P, White SK, Yellon DM, Hausenloy DJ. Myocardial reperfusion injury: looking beyond primary PCl. Eur Heart J. 2013;34:1714-22.

4. Hausenloy DJ, Yellon DM. Ischaemic conditioning and reperfusion injury. Nat Rev Cardiol. 2016;13:193-209.

5. Gross ER, Hsu AK, Gross GJ. Opioid-induced cardioprotection occurs via glycogen synthase kinase beta inhibition during reperfusion in intact rat hearts. Circ Res. 2004;94:960-6.

6. Obame FN, Plin-Mercier C, Assaly R, Zini R, Dubois-Rande JL, Berdeaux A, et al. Cardioprotective effect of morphine and a blocker of glycogen synthase kinase 3 beta, SB216763 [3-(2,4-dichlorophenyl)-4(1-methyl-1H-indol-3-yl)$1 \mathrm{H}$-pyrrole-2,5-dione], via inhibition of the mitochondrial permeability transition pore. J Pharmacol Exp Ther. 2008;326:252-8.

7. Gross ER, Hsu AK, Gross GJ. Diabetes abolishes morphine-induced cardioprotection via multiple pathways upstream of glycogen synthase kinase-3beta. Diabetes. 2007:56:127-36.

8. Kim JM, Jang YH, Kim J. Morphine and remifentanil-induced cardioprotection: its experimental and clinical outcomes. Korean J Anesthesiol. 2011;61:358-66.

9. Wong GT, Li R, Jiang LL, Irwin MG. Remifentanil post-conditioning attenuates cardiac ischemia-reperfusion injury via kappa or delta opioid receptor activation. Acta Anaesthesiol Scand. 2010:54:510-8.

10. Mahrholdt H, Wagner A, Holly TA, Elliott MD, Bonow RO, Kim RJ, et al. Reproducibility of chronic infarct size measurement by contrast-enhanced magnetic resonance imaging. Circulation. 2002;106:2322-7.

11. Xenopoulos NP, Leesar M, Bolli R. Morphine mimics ischemic preconditioning in human myocardium during PTCA. JACC. 1998:31:65A Abstract.

12. Rentoukas I, Giannopoulos G, Kaoukis A, Kossyvakis C, Raisakis K, Driva M, et al. Cardioprotective role of remote ischemic periconditioning in primary percutaneous coronary intervention: enhancement by opioid action. JACC Cardiovasc Interv. 2010;3:49-55.

13. Gwag HB, Kim EK, Park TK, Lee JM, Yang JH, Song YB, et al. Cardioprotective effects of intracoronary morphine in ST-segment elevation myocardial infarction patients undergoing primary percutaneous coronary intervention: a prospective, Randomized Trial. J Am Heart Assoc. 2017:6:1-9.

14. Murphy GS, Szokol JW, Marymont JH, Avram MJ, Vender JS. Opioids and cardioprotection: the impact of morphine and fentanyl on recovery of ventricular function after cardiopulmonary bypass. J Cardiothorac Vasc Anesth. 2006;20:493-502

15. Zhang R, Shen L, Xie Y, Gen L, Li X, Ji Q. Effect of morphine-induced postconditioning in corrections of tetralogy of fallot. J Cardiothorac Surg. 2013;8:76.

16. Wong GT, Huang Z, Ji S, Irwin MG. Remifentanil reduces the release of biochemical markers of myocardial damage after coronary artery bypass surgery: a randomized trial. J Cardiothorac Vasc Anesth. 2010;24:790-6.

17. Atar D, Arheden H, Berdeaux A, Bonnet $J$, Carlsson M, Clemmensen P, et al. Effect of intravenous TRO40303 as an adjunct to primary percutaneous coronary intervention for acute ST-elevation myocardial infarction: MITOCARE study results. Eur Heart J. 2015;36:112-9.

18. Cung TT, Morel O, Cayla G, Rioufol G, Garcia-Dorado D, Angoulvant D, et al. Cyclosporine before $\mathrm{PCl}$ in patients with acute myocardial infarction. N Engl J Med. 2015:373:1021-31.

19. Ferdinandy P, Hausenloy DJ, Heusch G, Baxter GF, Schulz R. Interaction of risk factors, comorbidities, and comedications with ischemia/reperfusion injury and cardioprotection by preconditioning, postconditioning, and remote conditioning. Pharmacol Rev. 2014;66:1142-74.
20. Bouhidel O, Pons S, Souktani R, Zini R, Berdeaux A, Ghaleh B. Myocardia ischemic postconditioning against ischemia-reperfusion is impaired in $\mathrm{Ob} /$ Ob mice. Am J Physiol Heart Circ Physiol. 2008;295:H1580-6.

21. Niodromitis EK, Zoga A, Vrettou A, Andreadou I, Paraskevaidis IA, Kaklamanis $L$, et al. The effectiveness of postconditioning and preconditioning on infarct size in hypercholesterolemic and normal anesthetized rabbits. Atherosclerosis. 2006;188:356-62.

22. Wu N, Zhang $X$, Jia $P$, Jia D. Hypercholesterolemia abrogates the protective effect of ischemic postconditioning by induction of apoptosis and impairment of activation of reperfusion injury salvage kinase pathway. Biochem Biophys Res Commun. 2015:458:148-53.

23. Xu Y, Ma LL, Zhou C, Zhang FJ, Kong FJ, Wang WN, et al. Hypercholesterolemic myocardium is vulnerable to ischemia-reperfusion injury and refractory to sevoflurane-induced protection. PLoS One. 2013;8:e76652.

24. Yetgin T, Magro M, Manintveld OC, Nauta ST, Cheng JM, den Uil CA, et al. Impact of multiple balloon inflations during primary percutaneous coronary intervention on infarct size and long-term clinical outcomes in ST-segment elevation myocardial infarction: real-world postconditioning. Basic Res Cardiol. 2014;109:403.

25. Siller-Matula JM, Specht S, Kubica J, Alexopoulos D, De Caterina R, Hobl EL, et al. Abciximab as a bridging strategy to overcome morphine-prasugrel interaction in STEMI patients. Br J Clin Pharmacol. 2016;82:1343-50.

26. Kubica J, Adamski P, Ostrowska M, Sikora J, Kubica JM, Sroka WD, et al. Morphine delays and attenuates ticagrelor exposure and action in patients with myocardial infarction. Eur Heart J. 2016;37:245-52.

27. Parodi G, Bellandi B, Xanthopoulou I, Capranzano P, Capodanno D, Valenti R et al. Morphine is associated with a delayed activity of oral antiplatelet agents in patients with ST-elevation acute myocardial infarction undergoing primary percutaneous coronary intervention. Circ Cardiovasc Interv. 2015:8:1-6.

28. Montalescot G, Van 't Hof AW, Lapostolle F, Silvain J, Lassen JF, Bolognese L, et al. Prehospital ticagrelor in ST-segment elevation myocardial infarction. N Engl J Med. 2014:371:1016-27.

29. Puymirat E, Lamhaut L, Bonnet N, Aissaoui N, Henry P, Cayla G, et al. Correlates of pre-hospital morphine use in ST-elevation myocardial infarction patients and its association with in-hospital outcomes and longterm mortality. Eur Heart J. 2016:37:1063-71.

30. Bonin M, Mewton N, Roubille F, Morel O, Cayla G, Angoulvant D, et al. Effect and safety of morphine use in acute anterior ST-segment elevation myocardial infarction. J Am Heart Assoc. 2018;7:1-8.

\section{Ready to submit your research? Choose BMC and benefit from:}

- fast, convenient online submission

- thorough peer review by experienced researchers in your field

- rapid publication on acceptance

- support for research data, including large and complex data types

- gold Open Access which fosters wider collaboration and increased citations

- maximum visibility for your research: over $100 \mathrm{M}$ website views per year

At $\mathrm{BMC}$, research is always in progress.

Learn more biomedcentral.com/submissions 